\title{
A Digital Individual Benefit Statement to Mitigate the Risk of Poverty in Retirement: The Case of Switzerland
}

\author{
Catherine Equey Balzli
}

Citation: Equey Balzli, Catherine. 2021. A Digital Individual Benefit Statement to Mitigate the Risk of Poverty in Retirement: The Case of Switzerland. Risks 9: 101. https:// doi.org/10.3390/risks9060101

Academic Editor: Mogens Steffensen

Received: 12 April 2021

Accepted: 8 May 2021

Published: 1 June 2021

Publisher's Note: MDPI stays neutral with regard to jurisdictional claims in published maps and institutional affiliations.

Copyright: (C) 2021 by the author. Licensee MDPI, Basel, Switzerland. This article is an open access article distributed under the terms and conditions of the Creative Commons Attribution (CC BY) license (https:/ / creativecommons.org/licenses/by/ $4.0 /)$.
Department of Business Administration, Haute Ecole de Gestion Geneva, Campus de Battelle, University of Applied Sciences of Western Switzerland (HES-SO), 17 rue de la Tambourine, 1227 Carouge, Switzerland; catherine.equey@hesge.ch

\begin{abstract}
Old-age retirement benefits are a major concern among the Swiss population but estimating one's revenue after retirement is challenging due to the Swiss social system's complexity. In Switzerland, as with many other countries, the risk of poverty for retiree people is high, especially for women who often work part-time. The research presented in this paper proposes a methodology to enable the development of a digital platform to provide Swiss citizens the means to verify that their retirement income will allow them to live decently when retired. The aim of the platform will be to allow insured people to plan for retirement in a simplified manner. The methodology used was both qualitative (focus group) and quantitative (surveys). The main results are recommendations for the scope and functionality for a digital platform to be developed. A main conclusion is the need to limit the platform's scope to old-age pension only (e.g., excluding survivors' or disability pensions). Moreover, an outcome regarding the functionalities is the proposition of scenarios such as postponed retirement, additional purchases in pension fund, or changes to individual status. The development of the platform is not included in the article.
\end{abstract}

Keywords: benefit statement; digital platform; retirement financial planning; social insurances

\section{Introduction}

Old-age retirement is clearly a highly topical issue of major importance because many changes have occurred. During the 20th century, the family was quite stable, with low divorce rates. Professional careers were also secure, with low unemployment rates. It was usual to work for the same company during one's entire career. International mobility was lower than it is today. The market was so profitable that pension funds could remunerate capital with 7\% interest rates and sometimes even more.

Recently, the situation has changed. In Switzerland, about $40 \%$ of weddings end in divorce (OFS 2020). One's professional career is no longer stable, and people change their job often and sometimes become unemployed. International mobility has exploded, especially in Switzerland. All these changes have influences on retirement benefits, especially the one coming from pension funds.

Furthermore, the financial market's poor profitability and low interest rates have increased uncertainties concerning retirement plans. Trust in pension funds is increasingly challenged, and employees are becoming ever more concerned.

According to a study made by banking specialists Crédit Suisse (2019), old-age retirement pension was the main concern among the Swiss in 2019. This concern has risen sharply over the last four years, from concerning $28 \%$ to $45 \%$ of Swiss citizens. The project presented in this article pursues a social goal: to help to reduce poverty for the elderly. Although Switzerland is often better off than other countries in terms of social insurance and standard of living, the situation in retirement is reversed. In 2017, OECD (2017) pointed out that the risk of poverty among citizens over 65 years of age was $19 \%$ in Switzerland compared to an OECD (Organization for Economic Co-operation and Development) average of $13 \%$ (only taking retirement benefits into account). This result is very surprising 
because Swiss spending on pensions is high (11\% of GDP compared with $9 \%$ in OECD countries). However, the pension received in Switzerland is lower, at $45 \%$ of the previous salary, compared to $63 \%$ in the OECD. It should be noted that these figures do not consider the non-mandatory pension scheme which complements the income for those retirees who participated in these funds. Otherwise, the OECD considers that "the poverty threshold is set at 50\% of median, equivalized household disposable income" (OECD 2017, p. 134). Consequently, it can be considered that the high wage levels in Switzerland have a strong impact on the poverty rate calculated by the OECD. Nevertheless, the phenomenon of poverty among the elderly is a problem of national importance in Switzerland. Not only Switzerland is concerned by elderly people poverty, as this phenomenon is also global. In a study concerning five different countries, Han et al. (2019) pointed out that people do not adequately plan savings for retirement. This research compared Korea, Japan, Germany, United States of America, and the United Kingdom.

In addition, retirement pensions in Switzerland are particularly complex because they are governed by numerous laws, ordinances, and regulations. Many risks (death, disability, old age, etc.) are insured by several subsystems (the three-pillar system). It is almost impossible for an insured person to estimate their total income after retirement. On the other hand — and this does not improve the situation —all insured persons know that they will experience a substantial reduction in their retirement income.

In this context, the research purpose is to conduct a preliminary analysis to develop a digital platform for providing insured persons with simplified access to information.

Therefore, the project was aimed at determining five major items: (1) the information needed by employees (kinds of insurance, information, and scenarios processed by the platform; (2) the specific scope of the platform; (3) the type, sources, and availability of the information that will be entered into the platform; (4) the necessary functionalities or requirements for a digital platform to compile information from many sources. Information which must enable the presentation of an employee's or a retired person's current financial coverage as well as the planning of their financial situation at retirement; (5) the way to forward (i.e., transfer to the platform) all information.

The project aim was not to develop a digital platform; rather, it was an exploratory research for developing such a platform. This exploratory study will be a critical success factor for limiting the risk of project failure and will provide the elements with which to prepare the tool's development. Therefore, the project presented in this article does not include the development of the digital platform, which will be the subject of a subsequent project.

\section{Literature Review}

On the one hand, social insurance programs are very complex, and benefit statements are difficult for individuals to understand (OECD 2008). On the other hand, insured people are very concerned with their financial situation after retirement (Crédit Suisse 2019). Literature affirms that providing information to people encourages financial retirement planning (OECD 2011; Larsson et al. 2009). Benefit statements are crucial for individuals to understand their situation and to make saving decisions (Larsson et al. 2009).

The authors have discussed best practices concerning benefit statements (OECD 2011; Fleishman-Mayer et al. 2013). They have pointed out, for example, that an Internet site providing information could be problematic for data protection even if it could be easier for individuals to access. However, the main difficulty in drawing up benefit statements seems to be the need to combine diverse sources of information, mainly public, occupational, and private, to obtain a comprehensive view of the pension benefits when one retires (OECD 2008). Moreover, the long-term forecast uncertainty and hypotheses to be taken complicate the presentation of an understandable benefit statement.

Fleishman-Mayer et al. (2013) presented the best practices for designing benefit statements a working paper based on a literature review (this working paper was not peer reviewed). Their study indicated the following: 
- The most important information to be presented is "the expected pension at the age of retirement" (OECD 2011, p. 19);

- Forecasts for early or postponed retirement or supplementary investments in pension funds are also requested (OECD 2011);

- Benefit statements must be adapted depending on insured people's age (Government Accountability Office 2005);

- Information on risks concerning savings values at retirement age should be presented (Vlaev et al. 2009);

- Information must be simplified by using shorter words and sentences and basic language (Morgan et al. 2002). Segmentation of information could also enhance understanding (Mayer and Moreno 2003);

- Policy and education actions are necessary to enhance retirement financial planning to insure financial stability when retired. To do so, individuals need accurate information easy to understand (Han et al. 2019);

- How information is presented has a psychological influence on understanding and decisions, e.g., by presenting smaller amounts with monthly benefits instead of capital assets (Benartzi and Thaler 2001). This point was not specific to benefit statements but also concerns investment decisions in general;

- Individuals prefer to receive information with premade decisions or a starting point, rather than having total freedom of choice with all possibilities. They prefer to be guided (Redmond 2011).

Apart from the papers quoted above and to the best of our knowledge, recent academic literature about retirement-benefit statements (digital or not) or retirement financial planning is scarce. Academic literature on retirement and its financial consequences is only indirectly linked to our research scope. For instance, Ramaswamy (2012) described the sustainability of pension schemes from a policy perspective. We found only one other paper concerning benefit statement, but it described benefit statement requirements for requirement plans (Forman and Scahill 2003). Moreover, this paper concerns the US and a static statement (with no planning or simulation). Saving choices, asset allocations, and contribution rates have also been studied (Gough and Niza 2011). The main frame of these publications is in social sciences, with studies of behavior or individual perception concerning retirement and financial consequences, which are not directly linked to this research. Currently, research on digital individual benefit statements is missing.

Contrariwise, numerous professional articles concern the Swiss laws governing the pensions system as well as the challenge of maintaining one's living standards when retired.

One difficulty concerning social insurances is that the Swiss pensions system is particularly complex and governed by numerous laws. Among other laws, the main laws are the federal Old Age and Survivors' Insurance Law (state pension), the Disability Insurance Law, the law that regulates the Occupational Benefit Plan for employees, and the Federal Law on Insurance. In addition to the complexity of these numerous laws, the sources of information are also wide. Therefore, the Swiss social security system is particularly complex to understand for non-specialists, and the following paragraph describe its key elements.

In Switzerland, all retired citizens receive a state pension. In addition, they may receive benefits from an occupational or private pension fund, and, importantly, personal savings could complete the pension plans (banks and insurances offer diverse possibilities). This model is called the three-pillar pension system. The most current and simplified presentation of the Swiss pension system presented in the professional literature is based on three-pillar schema, as described in Figure 1. It encompasses all financial instruments to maintain one's living standards at retirement. 


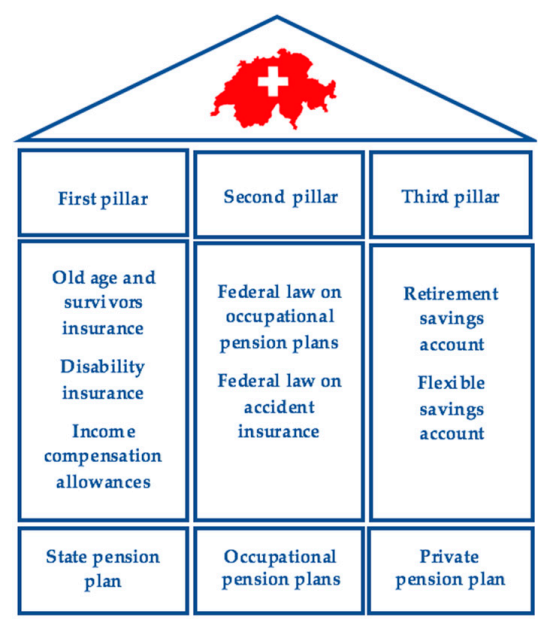

Figure 1. Swiss pension plan system (Swissinfo 2017).

The first pillar or the state pension plan includes several insurance programs such as old age, survivors, and disability insurance. They are mandatory for all Swiss residents but insufficient to preserve one's prior living conditions-these are the bare minimum. The second pillar is based on occupational pension plans and accident insurance, and it complements the first pillar for employees. Pension plans and accident insurance are mandatory for almost all employees. The self-employed can join if they want, but it is not obligatory. The first and second pillars' benefits should allow workers to earn approximately $60 \%$ of their final salary after retirement. The third pillar is a personal decision: individuals can choose to increase the part of their last income not covered by the first two pillars. Insured people can enhance their financial situation at retirement by increasing their contributions to the second pillar, but this option is limited. Savings, in the third pillar, are the main tool to ensure that policyholders maintain their standard of living in retirement. However, savings decisions must be made based on relevant and understandable information which are currently missing or difficult to obtain.

To allow people to understand their current situation in terms of future retirement benefits, state, insurance programs, and banks provide much information or many Internet links to estimate their pensions. Concerning the first pillar, an online calculator is available on the Swiss Confederation Internet site. This tool is accurate and efficient but concerns only the first pillar. For the second pillar, insured people mainly receive a paper benefit statement. Several banks and insurance programs offer calculators, but they are very simple tools based on one's situation (marital status, sex, and age) and with a few hypotheses. Banks also develop solutions to determine the lack of income at retirement to sell financial products. We have studied the existing tools very carefully and, currently, none of the systems offered so far gathers the precise information of the three pillars of the pension system. Furthermore, existing tools do not allow simulations of scenarios with an impact on the first two pillars. Some insurances companies, such as Swiss Life and Retraites Populaires, offer portals that combine second and third pillar data. Retraites Populaires is the more advanced portal with the possibility to simulate some simple scenarios. However, the exact data of the first pillar is not included in their results. The main problem to be solved is the difficulty of aggregating the actual information extracted from the existing systems (three pillars). There is a lack of consolidation of information from the three pillars in a single system and forecasting is not possible. The aim of the platform to be developed is to fulfill this gap. In the German-speaking part of Switzerland, the Swiss Fintech Innovations (SFTI) is an organization that is also working on a project similar to ours: https:/ / swissfintechinnovations.ch/projects /vorsorge-cockpit-pension-cockpit/ (accessed on 11 May 2021). Their project is more oriented towards gathering all the data of an insured person in a single database. We are in contact with SFTI and regularly share our progress and results with them. A digital platform allowing insured people to check their 
retirement benefits will also seeks to bridge the gap that Switzerland has with countries such as the UK and Canada that have advanced public services. For instance, the UK Check your State Pension forecast service (available here: https:/ / www.gov.uk/check-state-pension? step-by-step-nav=c0ff9296-e91e-40d1-97bd-008026e90426 (accessed on 11 May 2021)), or the Canadian service (CPP retirement pension available here: https:/ / www.canada.ca/ en/services/benefits/publicpensions /cpp/cpp-benefit/amount.html (accessed on 11 May 2021)) are platforms with the same aim as the one described in this article. Switzerland is clearly behind other countries and it worsens the risk of poverty at retirement. The development of a digital platform allowing the insured to have a simplified access to the estimation of all their pension assets will help to reduce this problem. In Switzerland workers must have more facilities to plan retirement. This is a societal challenge as simulations of savings or life choices will be possible on the platform to make decisions to improve income at retirement through supplementary savings for instance.

Moreover, some decisions (e.g., investment in a private pension plan) also have complex tax impacts, which are difficult to identify due to the numerous tax laws (each canton and the confederation has different tax laws). It is particularly difficult to have a global vision of one's capital and forthcoming income upon retirement. Planning is almost impossible without the help of a financial specialist. Thus, to be able to plan for retirement, employees need a simple and ergonomic presentation of their financial situation when they retire and the ability to plan different scenarios to help with decision-making. Insured persons must be able to efficiently check and plan their financial situation when they retire to maintain as much of their living standards as possible.

In conclusion, most employees in Switzerland receive a printed benefit statement once a year or can consult a static electronic statement through a website that does not allow forecasting or planning. This has not benefitted from the digital revolution. Switzerland is behind concerning the digitalization of its retirement-benefit statements and planning, mainly because of the complexity of the Swiss insurance system and political reasons. The functionalities of a digital platform must be carefully studied before it is developed. To the best of our knowledge, academic literature has never described such functionalities.

Moreover, digitalization seems simple, but as stated in Schulz et al. (2016), "One of the most important economic and social development of our times is the rise of the platform as a business and organizational model. [ ... ] The concept may sound simple, but it is radically changing businesses [ ... ] any industry for which information is an important ingredient is a candidate for the kind of disruption that is enabled by platforms. [ . . . ] The tricky part is that the solution needs to fit the requirements of all its players" (pp. 56-59). The aim of this research project is to determine scientifically the requirements of a digital platform to provide benefit statements. A modern tool such as a digital platform is needed to present a simplified retirement account balance and for people to plan their retirement while considering different scenarios (new investments in their retirement fund, marriage, divorce, real estate investments, etc.).

The objective of the project presented in this article is to determine the scope and functionalities of a digital platform that will allow insured people to plan their financial situation in retirement by carrying out certain changes (according to proposed scenarios). This project does not include the IT development of the digital platform and, for the second part of the project, a grant request is underway at Innosuisse (research funding agency of the Swiss Confederation).

\section{Methodology}

Understanding a complex subject requires different perspectives. The results must also be corroborated to increase their reliability. Therefore, triangulation was appropriate for designing a digital platform for financial retirement forecasting. As described by Patton (1999), we used methods triangulation (p. 5). The first method type used was qualitative. A focus group of social insurance specialists was gathered to design the platform's scope and functionalities. Focus groups are well fitted for qualitative and 
exploratory research in social sciences (Wilkinson 1998). Due to the complexity of the Swiss social system and the segmented knowledge of the actors (between the three pillars), interactions between the experts were necessary to design the whole framework of the future platform and interviews would not have been sufficient. The second methodology used was quantitative, and two surveys were conducted with insured people. Therefore, to achieve the research goal, qualitative, and quantitative approaches were applied to different groups of people, as described hereafter.

This research project was broken down into three main phases. The first step was to review the stakeholders, literature, laws, and ecosystem (concerned organizations, government, employees, employers, etc.) to know all of the stakeholders (which was also useful to form the focus group), academic research results concerning benefit statements, all laws and their impact on calculations; the sources of information (including difficulties in obtaining information), and the manner of transferring data.

Secondly, between April 2019 and July 2020, we conducted six focus groups with relevant experts chosen during the first step. This part was qualitative. A focus group was formed by five specialists from two of Geneva's main pension funds (second pillar), one IT expert and one business expert from the Swiss Central Compensation Office (first pillar), two retirement professionals from banks, and two managers with social insurance expertise from two audit firms (mainly the third pillar). The focus group meetings were carefully scheduled, and documentation was prepared in advance. The research team prepared for each focus group meeting and by pillar, all laws and regulation concerned, all contributions and benefits possible, and all the necessary information to be provided by individuals wanting to calculate their benefits at retirement. To collect the data, the method used was a thorough transcript of all discussions by a research assistant. Based on these records, the discussions and decisions were summarized in minutes by the professor in charge and the minutes send to all focus group members and discussed with the participants during the next meeting for potential modifications. Each of the minutes were approved by all focus group members and were used to build the questionnaire for quantitative analysis. The focus group's role was to propose which insurance programs, scenarios, and information must be retained for the platform, based on their experience. For the choices, a simplified system was always the priority. Therefore, the focus group outline was based on (1) each pillar of the Swiss social system and, (2) the five categories of decisions that had to be taken to propose the functionalities and scope. We have structured the topics to be debated as follows: first, the desired "output" was discussed, i.e., the types of benefits or pensions that will have to be returned by the Digital Individual Benefit Statement (DIBS) application at the end of the simulation. This was the scope of the platform. Second, the types of "inputs" or information that should be entered into the DIBS platform to return the sum of projected pensions at the end of the simulation were selected and described. Concerning the inputs, the question of how to transfer the information to the DIBS platform was an important item (e.g., Does the insured person have to enter the information manually? Does it have to be scanned? Is it necessary to provide a barcode or an interface?). The opinions were divided, with some experts wanting to use modern technologies (scanning or barcodes) and others advocating manual input to train users to read their benefit statements. The third issue (but the second most important category of decisions) deliberated was the necessary scenarios to be proposed in the DIBS platform. The focus group members retained seven scenarios, also called the platform's functionalities. Finally, discussions also focused on the types of technology to be used to support the platform, e.g., an Internet site or a mobile application.

The third phase comprised two surveys (quantitative methodology) of insured persons (possible future users of the platform). The first survey was conducted by CPEG (Caisse de prévoyance de l'Etat de Genève (Geneva State pension fund)) between July and September 2019. More than 56,000 insured persons were contacted through the CPEG newspaper, and we received 184 answers $(0.33 \%$ answer rate, certainly explained by the holiday period and the contact mode). The second survey was conducted with FER (Fédération des Entreprises Romandes Genève (Geneva firms' association)) members in February 2020. 
The FER contacted more than 27,000 companies by email, and we received 702 answers (2.6\% answer rate). To conduct the surveys, a short questionnaire was designed on Google Forms that included 11 questions (see Appendix A for more details). It could be filled out in $7 \mathrm{~min}$. The first part of the questionnaire was intended to determine the profile of the insured persons most likely to use the DIBS platform (in terms of gender, age, and income). Then, the questionnaire asked which benefits from the first and second pillars (in separate questions) the respondents prioritized, which scenarios were the most important to simulate, and, finally, which IT tools they preferred to use. Finally, the respondents could include remarks or requests in an open section (text input). Confidentiality was ensured for the respondents, but they could provide an email address to receive the results (this field was not mandatory).

\section{Results}

Using qualitative (focus group) and quantitative (survey) methodologies, the research results show the scope and functionalities for a digital platform to be developed. Therefore, the results are described hereafter with respect to the two phases (qualitative and quantitative). The final choices are presented at the end of the section.

The main objective of the focus groups was to determine the functionalities and scope of the future DIBS platform for forecasting and planning the income of retired people. One important challenge was to simplify a very complex reality by making choices to narrow the scope and functionalities without losing important information.

\subsection{Scope of the DIBS Platform Proposed by the Focus Group}

Following the focus group meetings, the members agreed that the DIBS platform's scope will be only old-age pensions. Therefore, survivors' pensions, disability pensions, auxiliary means, and supplementary benefits were excluded from the DIBS's scope. Allowances for loss of earnings, family allowances, and other social insurance programs were also excluded from the scope of the DIBS (at least for the first stage of IT development).

In addition, conditions were set to limit the scope of and thus simplify the model. The focus group members decided that only information valid at the legal retirement age would be returned by the DIBS (not before or after). The information returned would only concern the insured person (not their spouse or family). Finally, pension fund changes would not be possible as a scenario (to develop only one interface with one pension fund system). Simplification was the main reason for these choices, but we also considered the frequency and importance (in terms of income) of the social security system's elements.

\subsection{Functionalities of the DIBS Platform Proposed by the Focus Group}

The focus group members agreed on scenarios with which to simulate the financial situation of the insured at retirement. The selected scenarios were as follows:

- No change (i.e., one's income, activity rate, and personal situation will not change until legal retirement age);

- Change of income (which can increase but also decrease for people who want to reduce their activity rate);

- Early or postponed retirement (in this case, the benefit given by the system will not be at the real retirement age but at the legal one, i.e., 65 years old for men and 64 years old for women);

- $\quad$ Retirement pension and capital (both, instead of only a pension) (Only for the second pillar);

- Supplementary investments in a pension fund (Only for the second pillar) when possible (to increase the benefit at retirement);

- $\quad$ Change in personal situation (marriage, divorce, newborn child, etc.);

- Withdrawal of capital (from a pension fund) for property acquisition (Only for the second pillar). 
Some other scenarios that were strongly demanded by the experts (unemployment or moving abroad, for example) were excluded because they involved a change of pension fund. The focus group decided that the DIBS model would only provide for the development of an interface with one pension fund software per user, as explained in Section 4.1.

\subsection{Technological Choices Made by the Focus Group}

A large majority of the focus group members favored the DIBS platform being developed on an Internet site to be useful for a larger group of users. In contrast, the academic team preferred to develop a mobile application.

Regarding the entry of information into the platform, again, the professional and academic experts did not share the same opinions. The professionals preferred manual inputs, and the academics preferred automated data entry. Both issues are still open.

Concerning the calculations to be carried out to determine one's old-age pension after simulation of a scenario, the two categories of experts agreed not to carry out the calculations within the DIBS platform but to develop an interface within the existing systems. Therefore, the DIBS platform will be linked to the Swiss confederation system used to calculate Swiss old-age retirement pensions, and an application programming interface (API) will be developed to connect the DIBS to the confederation's system. The Swiss Central Compensation Office agreed to recognize the DIBS platform and to automatically return the information in the DIBS. The pension fund situation is more complicated because there are more than 1500 pension funds in Switzerland and about 500 IT systems. The focus group also decided to develop an API but only with two pension funds to begin. The pension funds must still be selected.

The choices made by the focus group became the subject of numerous discussions and as already mentioned, were mainly based on the need to simplify the inputs requested for when the insured persons use the platform, as well as to simplify the outputs given back by the platform. The focus group also decided to help insured persons to better understand the Swiss social insurance system and, in particular, to allow them to estimate their savings and retirement benefits so that they can continue the lifestyle to which they are accustomed, once they retire.

Despite the merits of these decisions, there were made by highly skilled professionals who are not Lambda-insured individuals, and so their requirements may be different. The main objective of the survey (quantitative phase) was therefore to validate the choices made by the group of experts, i.e., to confirm whether these choices correspond to the needs of the insured persons.

\subsection{Statistical Results}

The typical profile of the survey respondents was a woman (CPEG 56\%; FER 56\%) in the 46- to 65-year-old age group (CPEG 82\%; FER 61\%) and had an income of more than CHF 100,000.- (Approximately USD 110,000 in September 2020) (CPEG 55\%; FER 45\%). As expected, older people with a comfortable income felt the most concerned.

The most requested information by all respondents was clearly old-age pension information for the first pillar, old-age and survivor's insurance, (CPEG 97\%; FER 98\%). For the second pillar, occupational pension plans, the most requested information by all respondents was also old-age pension information (CPEG 97\%; FER 98\%).

The survey responses confirmed that the DIBS will return only old-age pension information because it was the most requested information in both surveys for both the first and second pillars. The risks of disability and death will therefore not be considered in the DIBS platform.

Concerning the platform's functionalities, the scenarios most requested by the survey's respondents were (1) simulation of early or postponed retirement (CPEG 83\%; FER 69\%); (2) no change in income or personal situation (CPEG 54\%; FER 89\%); (3) taking part of their retirement in capital and part in pension (CPEG 54\%; FER 57\%); (4) supplementary 
payments to their pension fund (CPEG 51\%; FER 59\%); and (5) changes in work income (CPEG 44\%; FER 54\%).

Notably, the preferred scenario for CPEG respondents was a simulation of early or postponed retirement, whereas the scenario most requested by employees of FER members was only to know their retirement situation without changes.

Finally, we asked the respondents about the technology they preferred to use. The most requested digital solution for DIBS was a website (CPEG 73\%; FER 69\%), followed by indifference (CPEG 16\%; FER 21\%). Therefore, a website was popular, and surprisingly, an application was unwanted.

In general, the results of the two surveys confirmed the focus group's proposals and allowed for the final choice of the DIBS platform's scope and functionalities, as described in the following section.

\subsection{Model for the Digital Individual Benefit Statement Platform}

After both phases of the research project, the focus group was reunited once again to present the survey results to make final decisions concerning the platform's scope and functionalities. As confirmed by the qualitative and quantitative methodologies, the platform's scope will be limited to old-age pension only (excluding survivors' or disability pensions, for instance). Both methodologies confirmed this choice.

Concerning the functionalities, the five scenarios selected by the survey respondents (see Section 4.4) were retained for the DIBS platform and will allow for simulations of changes in old-age pensions at retirement. Nevertheless, the expert group also decided to account for two additional scenarios despite a survey response rate of about $30 \%$ because, according to their experience, insured people frequently request them: withdrawal of capital from a pension fund for property acquisition (CPEG 30\%; FER 35\%) and changes in one's personal situation (marriage, divorce, etc.) (CPEG 29\%; FER 39\%).

Therefore, the functionalities will involve planning the following seven scenarios:

(1) Simulation of early or postponed retirement;

(2) No change in income or personal situation;

(3) Taking a portion of one's retirement in capital and a portion as a pension;

(4) Supplementary payments into the pension fund;

(5) Changes in work income;

(6) Withdrawal of capital for property acquisition;

(7) Changes in one's personal situation (marriage, divorce, etc.).

Based on the results, a platform model was designed and is represented hereafter in Figure 2:

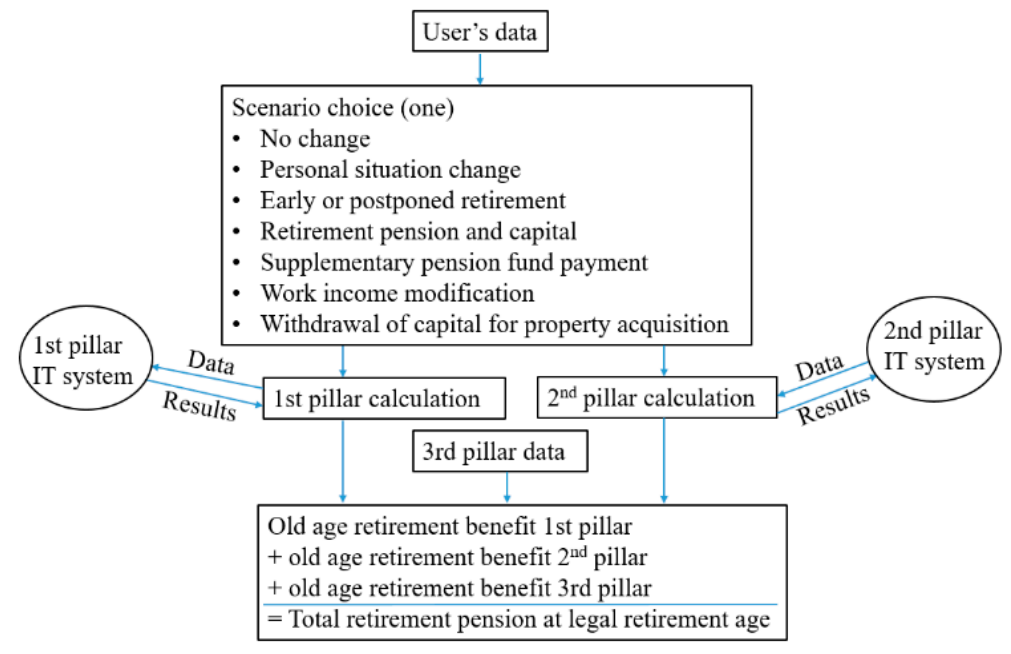

Figure 2. DIBS platform model. 
One important element pointed out by the focus group's experts is the reliability of the data used. The modeled platform foresees that the real data of the citizens are retrieved directly from the IT systems of its pension funds through application programming interface. The results of the scenarios will also be calculated in the existing systems. The connection with the current tools is a key success factor to obtain reliable data and a major difference with calculators currently offered by banks and insurance companies. Finally, the choice of technical solution with which to develop the platform is still open and will be decided during the IT development with the future IT partners. However, the need to develop a high data security system has been strongly emphasized.

In addition to the platform modeling and to present the decision more easily, the academic research team finally prepared a blueprint of the future platform. The blueprint presents future screens of the DIBS platform to illustrate the presented information. Each screen also contains information on where the information come from, in which screen the results or information must be forwarded, and how it must be presented (with presentation differences by pension fund). Each screen was submitted to the focus group and discussed before validation. The blueprint will be used for the IT development and will be the basis of the following phase.

\section{Limitations and Conclusions}

A modern tool such as a digital platform is needed to present a simplified individual retirement statement and to allow users to plan their retirement while considering different scenarios (new investments into retirement funds, marriage, divorce, postponed retirement, etc.). The main objective of the platform will be to give users a tool with which to check where their savings and accumulation for retirement stand relative to the goal they are pursuing and to take decisions accordingly (regarding supplemental savings, purchasing property, etc.). Literature Larsson et al. (2009) and Fleishman-Mayer et al. (2013) has shown that providing understandable information to people encourages financial retirement planning. The DIBS platform to be developed will allow policyholders to continue the lifestyle to which they are accustomed, once they retire or, depending on their revenues and wealth, the digital platform will help them to take saving decisions to protect themselves from the risk of poverty in retirement. Therefore, the aim of our project was to determine the specific scope and functionalities of a digital platform to allow easier retirement financial planning with different scenarios. The development of DIBS pursues a social innovation more than a technology-based innovation. The project did not include the development of the digital platform, which will be the subject of a subsequent project.

The DIBS platform's initial scope (the project's starting point) was the whole pension system. The platform's scope was carefully studied because the Swiss pension system is complex in terms of its laws, multiple sources of information, tax impacts, and calculations, and needs a simplified presentation. The OECD (2008) found that the main difficulty of drawing up benefit statements is combining diverse sources of information, mainly public and private, to obtain an accurate view of one's pension benefit when they retire, and we found that desegregation and segmentation of old-age pension associated information as a major issue to conduct our research.

Our research confirms previous research findings. Schulz et al. (2016) pointed out that the difficulty of developing a digital tool is not the IT development but obtaining a solution that will fit the requirements of future users. We also highlighted these difficulties, and our research foundation was to carefully study the future users' needs which are the core of the research presented in this paper. Concerning benefit statement design, literature Morgan et al. (2002) and Mayer and Moreno (2003) have argued that the best practice is to present simplified or segmented information. In accordance, with this finding, the focus groups proposed to limit the results given by the platform to only old-age pensions excluding, for instance, survivors' pensions or disability pensions. To simplify the information given to citizen, we also limited the number of scenarios possible and excluded the ones implicating a pension fund change (e.g., in case of unemployment). This is also 
in line with the findings of Redmond (2011) who stated that individuals prefer premade decisions. The research results (from the focus group and surveys) confirmed two authors' previous findings (OECD 2011) which proposed to present only the old-age pension and to forecast early or postponed retirement, and supplementary investments in pension funds. On the other hand, Benartzi and Thaler (2001)'s assertion that the presentation of smaller amounts with monthly benefits instead of capital assets and its psychological influence on understanding and decisions was never mentioned during the focus groups. Finally, the authors' affirmation that benefit statements must be adapted depending on insured people's age (Government Accountability Office 2005) was also never pointed out by the research's participants. On the contrary, we decided during focus groups to present only the benefit statement at retirement age.

Compared to previous research, our study brought new results concerning the functionalities. We highlighted seven simulations scenarios to estimate retirement benefits with the DIBS platform (see Section 4.5). Among these seven scenarios, only two (early or postponed retirement and supplementary investments into one's pension funds) were described by authors in previous research (OECD 2011; Government Accountability Office 2005). The other scenarios have never been described in the literature. A model of a digital platform allowing financial planning for retirement was, to our knowledge never described in the literature.

Our research has scientifically provided the scope and the necessary functionalities of a digital platform for planning retirement, financially. Some of the results confirmed previous research, while others are new. The triangulation methodology allowed the decisions taken to be scientifically validated and will enable us to move forward in our search for a partner for the IT development of DIBS.

Nevertheless, the results are subject to certain limitations. First, the study only concerns Switzerland, and regarding social insurance programs, the systems and laws are different in all countries. This could affect some of the results, and the model may not be relevant for other states. Second, one of the pension funds chosen for the survey-the CPEG - is a state (Geneva canton) pension fund, and its insured persons represent only state workers and not the entire population. State pension funds are generally safer than private pension funds and have better conditions. This could have influenced the survey respondents' answers. In addition, the relatively low response rate (certainly due to the summer period, in the case of the CPEG survey) may have also biased the results. However, these issues were partially corrected by the FER's survey, which presented a higher response rate by younger respondents and which was more representative of the Geneva population. The last limitation to our study is that the project has not yet been entirely completed. During the IT-development process, modifications may occur, which can modify the platform's scope and functionality choices.

Further research in other countries and concerning best practices for benefit statements will be pertinent. Research on the ergonomics of a digital platform for retirement-benefit planning would also be very valuable. Benartzi and Thaler (2001) confirmed that how information is presented has important psychological impacts on understanding and decisions. However, the most useful action at this point is to proceed to the IT development to highlight problems that have not yet been detected.

To conclude, it is particularly astonishing that in Switzerland, we can check our bank assets via an e-banking system but not for our pension assets. We hope that this research will help to fill this gap.

Funding: This research was funded by RCSO \& EM, University of Applied Sciences of Western Switzerland (HES-SO).

Institutional Review Board Statement: Not applicable.

Informed Consent Statement: Not applicable. 
Data Availability Statement: The data presented in this study are available on request from the corresponding author. The data (for instance surveys' answers) are not in appendix because the research was made in the French speaking part of Switzerland and questionnaire, minutes, reports were in French.

Acknowledgments: The support of the focus group members is gratefully acknowledged. The author would also like to thank Jessica Angelone for her valuable contribution.

Conflicts of Interest: The author declares no conflict of interest.

\section{Appendix A. Questionnaire: Planning your Financial Situation at Retirement}

The purpose of this questionnaire is to understand your requirements regarding the planning and forecasting of your financial situation at retirement: All data will be handled confidentially.

\section{Gender:}

Woman

Man

$\square$ Other/do not wish to answer

2. Age range:

Under 25 years old

Between 25 and 35 years old

Between 36 and 45 years old

Between 46 and 55 years old

Between 56 and 65 years old

Over 65 years old

$\square$ Other/do not wish to answer

3. Current gross income:

Under CHF 70,000.-

Between CHF 70,000.- and CHF 86,000.-

Between CHF 86,001.- and CHF 100,000.-

$\square$ Between CHF 100,001.- and CHF 150,000.-

Above CHF 150,000.-

$\square$ Other/do not wish to answer

4. Would you be interested in a simulation of your pension at retirement?

$\square$ Yes

$\square$ No

5. Would you prefer a:

$\square$ Simplified estimation, based on your average annual salary

$\square$ Detailed estimation, based on your historical annual salaries

6. Select six scenarios that you would like to be able to choose in planning your financial situation at retirement:

No change in current income or personal situation

Changes to work income

$\square$ Simulation of early or postponed retirement

$\square$ Drawing a portion of one's retirement pension in capital and maintaining a portion as a pension

$\square$ Supplementary payments into the pension fund

$\square$ Changes in one's personal situation (marriage, divorce, children)

$\square$ Withdrawal of capital for property acquisition

$\square$ Transition to self-employment 
$\square$ Unemployment situation

Other/do not wish to answer

7. Select the two most important 1st pillar benefits that you would expect from the simulation of the scenarios proposed in question six:

$\square$ Old-age pension

$\square$ Survivor's pension

Orphan's pension

Child(ren)'s pension

Disability pension

Supplementary benefits

$\square$ Other/do not wish to answer

8. Select the two most important 2 nd pillar benefits that you would expect from the simulation of the scenarios proposed in question six:

Old-age pension

$\square$ Survivor's pension

Orphan's pension

Child(ren)'s pension

Disability pension

Supplementary benefits

$\square$ Other/do not wish to answer

9. Regarding a digital solution that would allow you to simulate your financial situation at retirement, would you prefer to use:

$\square$ A website

$\square$ A mobile app (iOS and Android)

No preference

Other/do not wish to answer

10. Do you have any other suggestions or comments that you would like to share with us about financial planning for retirement?

11. If you agree to be contacted in order to answer additional questions, please provide your email address.

Thank you for your participation!

\section{References}

Benartzi, Shlomo, and Richard H. Thaler. 2001. Naive Diversification Strategies in Defined Contribution Saving Plans. American Economic Review 91: 79-98. [CrossRef]

Crédit Suisse. 2019. La prévoyance vieillesse reste en tête, la confiance envers les institutions chute in Baromètre des préoccupations du Crédit Suisse. Available online: https://www.credit-suisse.com/about-us/fr/rapports-recherche/etudes-publications/barometredes-preoccupations.html (accessed on 12 February 2020).

Fleishman-Mayer, Lauren A., Angela A. Hung, Joanne K. Yoong, Jack Clift, and Caroline Tassot. 2013. Designing Better Pension Benefits Statements: Current Status, Best Practices and Insights from the Field of Judgment and Decisionmaking. SSRN Electronic Journal 1-13. [CrossRef]

Forman, Jonathan B., and Patricia L. Scahill. 2003. Issues for Phased Retirement in Defined Benefit Plans. North American Actuarial Journal 7: 75-84. [CrossRef]

Gough, Orla, and Claudia Niza. 2011. Retirement Saving Choices: Review of the Literature and Policy Implications. Journal of Population Ageing 4: 97-117. [CrossRef] 
Government Accountability Office. 2005. Social Security Statements: Social Security Administration Should Better Evaluate Whether Workers Understand Their Statements. Available online: https:/ /www.gao.gov/assets/250/245914.pdf (accessed on 12 June 2020).

Han, Jihyung, Ko Daekyun, and Choe Hyuncha. 2019. Classifying Retirement Preparation Planners and Doers: A Multi-Country Study. Sustainability 11: 2815. [CrossRef]

Larsson, Lena, Annika Sundén, and Ole Settergren. 2009. Pension Information. OECD Journal: General Papers 2008: 131-71. [CrossRef]

Mayer, Richard E., and Roxana Moreno. 2003. Nine Ways to Reduce Cognitive Load in Multimedia Learning. Educational Psychologist 38: 43-52. [CrossRef]

OECD. 2008. Improving Financial Education and Awareness on Insurance and Private Pensions. Available online: https://www.oecd. $\mathrm{org} / \mathrm{daf} /$ fin/financial-education/improvingfinancialeducationandawarenessoninsuranceandprivatepensions.htm (accessed on 21 September 2020).

OECD. 2011. Communicating Pension Risk to DC Plan Members: The Chilean Case of a Pension Risk Simulator. Available online: https:/ / www.oecd.org/daf/fin/private-pensions/WP28_\%20CommunicatingPensionRiskToDCPlanMembers.pdf (accessed on 21 September 2020).

OECD. 2017. Pensions at a Glance 2017: OECD and G20 Indicators. Paris: OECD Publishing. [CrossRef]

OFS. 2020. Divorces-Démos 1/2020 | Publication | Office fédéral de la statistique. Office fédéral de la statistique. Available online: https:/ / www.bfs.admin.ch/bfs/fr/home/statistiques/population/mariages-partenaires-divorces/divortialite.assetdetail. 13307849.html (accessed on 23 March 2021).

Patton, Michael Q. 1999. Enhancing the quality and credibility of qualitative analysis. HSR: Health Services Research 34: 1189-208. Available online: https:/ / www.semanticscholar.org/paper/Enhancing-the-quality-and-credibility-of-analysis.-Patton/d85cb284 822ebcfea711c9e340c61c8df033cd1c (accessed on 14 June 2020). [PubMed]

Ramaswamy, Srichander. 2012. The Sustainability of Pension Schemes. SSRN Electronic Journal, 1-25. [CrossRef]

Redmond, William. 2011. Book Review: Rational Choice in an Uncertain World: The Psychology of Judgment and Decision Making. Journal of Macromarketing 31: 322-23. [CrossRef]

Morgan, M. Granger, Fischhoff Baruch, Bostrom Ann, and Cynthia J. Atman. 2002. Risk Communication: A Mental Models Approach. New York: Cambridge University Press, p. 366, ISBN 0-521-80223-7 (cloth) 0-521-00256-7 (paper). [CrossRef]

Schulz, Annette, Drazen Nikolic, and Julia Speicher. 2016. Platform Revolution: How to Make Networked Markets Work for You. Performance 8: 54-63. Available online: https://www.yumpu.com/en/document/read/55885395/platform-revolution-how-tomake-networked-markets-work-for-you (accessed on 22 February 2020).

Swissinfo. 2017. Switzerland's Three-Pillar-Swiss Insurance System for Retirement, Death and Disability. Available online: https://www. swissinfo.ch/eng/pillars-of-society_the-three-swiss-pension-pillars-explained/42995426 (accessed on 22 February 2020).

Vlaev, Ivo, Nick Chater, and Neil Stewart. 2009. Dimensionality of Risk Perception: Factors Affecting Consumer Understanding and Evaluation of Financial Risk. Journal of Behavioral Finance 10: 158-81. [CrossRef]

Wilkinson, Sue. 1998. Focus group methodology: A review. International Journal of Social Research Methodology 1: 181-203. [CrossRef] 